\title{
Promoção de crescimento e indução de resistência à antracnose por Trichoderma spp. em pepineiro
}

\author{
Veronica Nogueira da Silva(1), Sylvia Dias Guzzo(1), Cleusa Maria Mantovanello Lucon ${ }^{(1)}$ e Ricardo Harakava(1) \\ (1)Instituto Biológico, Centro de Pesquisa e Desenvolvimento de Sanidade Vegetal, Laboratório de Bioquímica Fitopatológica, \\ Avenida Conselheiro Rodrigues Alves, no 1.252, Caixa Postal 12.898, CEP 04010-970 São Paulo, SP. E-mail: veronicans@gmail.com, \\ guzzo@biologico.sp.gov.br, mantova@biologico.sp.gov.br, harakava@biologico.sp.gov.br
}

Resumo - O objetivo deste trabalho foi determinar o efeito de 60 isolados de Trichoderma e do produto Trichodermil na promoção do crescimento e na indução de resistência sistêmica à antracnose, causada por Colletotrichum lagenarium em pepineiro, além de identificar as espécies dos isolados de Trichoderma spp. efetivas como indutores de resistência. Nos experimentos de promoção de crescimento, os isolados de Trichoderma spp. foram submetidos à inoculação no substrato e, após 21 dias, a massa de matéria seca da parte aérea das plantas foi mensurada. Nos experimentos de indução de resistência, os isolados que promoveram crescimento foram introduzidos no substrato, na base das plantas, sete dias antes da inoculação de $C$. lagenarium nas folhas. $\mathrm{O}$ isolado que apresentou melhor desempenho foi avaliado quanto à redução dos sintomas de antracnose, em aplicações aos 3, 7 ou 14 dias antes da inoculação do patógeno, e quanto à capacidade de aumentar a atividade de peroxidase. Dezenove isolados e o Trichodermil promoveram o crescimento de pepineiro em até $100 \%$ e conferiram proteção à antracnose em até 88,39\%. O isolado IB 31/06 reduziu a severidade da doença nos intervalos de tempo avaliados. Não foi observado aumento significativo de peroxidase, sete dias após o tratamento com IB 31/06, nas plantas tratadas e infectadas com o patógeno, em comparação às plantas infectadas. O sequenciamento gênico dos dezenove isolados permitiu a identificação de sete espécies distintas de Trichoderma.

Termos para indexação: Colletotrichum lagenarium, Cucumis sativus, antagonismo, biocontrole, indução de proteção sistêmica, peroxidase.

\section{Growth promotion and resistance induction against anthracnose in cucumber using Trichoderma spp.}

\begin{abstract}
The objective of this work was to determine the effect of 60 isolates of Trichoderma and the product Trichodermil on the growth promotion and on the induction of systemic resistance to anthracnose caused by Colletotrichum lagenarium in cucumber, and to identify isolates of Trichoderma spp. effective as resistance inductors. In the assays of growth promotion, the Trichoderma spp. isolates were inoculated in the substrate and, after 21 days, the shoot dry weight of the plants was measured. In the experiments of resistance induction, the isolates which promoted growth were inoculated in the substrate, at the base of the plants, seven days before $C$. lagenarium inoculation in the leaves. The isolate which showed the best performance was evaluated for anthracnose symptom reduction in applications at 3,7 or 14 days before the pathogen inoculation, and for its ability of increasing the peroxidase activity. Nineteen isolates and Trichodermil promoted cucumber growth up to $100 \%$ and conferred plant protection against anthracnose up to $88.39 \%$. The isolate IB 31/06 reduced the disease severity at the evaluated time intervals. No significant peroxidase increase was observed seven days after treatment with IB 31/06, in the plants treated and infected with the pathogen, in comparison to infected plants. Gene sequencing of the 19 isolates allowed for the identification of seven Trichoderma different species.
\end{abstract}

Index terms: Colletotrichum lagenarium, Cucumis sativus, antagonism, biocontrol, induced systemic protection, peroxidase.

\section{Introdução}

O fungo Colletotrichum lagenarium (Pass.) Ellis \& Halsted, agente causal da antracnose em cucurbitáceas, apresenta como sinonímias Colletotrichum orbiculare
(Berk. \& Mont.) Arx. e Colletotrichum gloeosporioides f. sp. cucurbitae (Berk. \& Mont.). Adoença é importante pela frequência com que ocorre e pelos danos que causa à cultura do pepino e em outras cucurbitáceas (Agrios, 2004; Rios et al., 2004). 
Os prejuízos causados pelo uso frequente de produtos químicos, para controlar doenças de plantas, motivam a busca de métodos alternativos de controle. Agentes de controle biológico como Trichoderma spp. e indutores de resistência bióticos e abióticos são alternativas ao uso de pesticidas (Perazzolli et al., 2008).

O potencial de Trichoderma spp., como agentes de biocontrole, é conhecido há mais de 60 anos, e muitos isolados são simbiontes de plantas e podem atuar no controle de fitopatógenos (Brotman et al., 2010). As espécies do gênero Trichoderma estão entre os antagonistas mais estudados, pois são encontradas naturalmente em quase todos os tipos de solo e agem contra fitopatógenos por diferentes mecanismos de ação como antibiose, micoparasitismo, produção de enzimas degradadoras de parede celular, competição por nutrientes e substrato, promoção do crescimento das plantas e indutores de resistência contra diversos patógenos, com efeitos benéficos para as plantas (Harman et al., 2004; Shoresh et al., 2005; Viterbo et al., 2005; Perazzolli et al., 2008; Vinale et al., 2008).

Em pepineiro (Cucumis sativus L.), Yedidia et al. (2003) verificaram que o isolado T-203 de Trichoderma asperellum, inoculado no sistema radicular, conferiu proteção sistêmica à mancha-angular causada por Pseudomonas syringae pv. lachrymans e reduziu em $80 \%$ os sintomas da doença. A proteção propiciada pelo agente de biocontrole foi associada ao acúmulo de mRNAs codificadores das enzimas de defesa fenilalanina amônia-liase e hidroperóxido liase. Raízes de pepineiro, tratadas com um isolado de T. harzianum, exibiram aumentos das atividades das enzimas quitinase, $\beta$-1,3-glucanase, celulase e peroxidase, observados até 72 horas após o tratamento (Yedidia et al., 2000).

Entretanto, a indução de resistência em plantas por espécies de Trichoderma tem sido pouco estudada, em comparação às pesquisas similares realizadas com rizobactérias promotoras de crescimento (Harman et al., 2004). No Brasil, os estudos relacionados à utilização de Trichoderma spp., no controle de doenças de plantas, têm focalizado efeitos diretos sobre fitopatógenos e não têm sido direcionados para o mecanismo indireto de ação que envolve a indução de resistência.

O objetivo deste trabalho foi determinar o efeito de 60 isolados de Trichoderma e do produto comercial Trichodermil na promoção do crescimento e na indução de resistência sistêmica à antracnose, causada por $C$. lagenarium em pepineiro, além de identificar as espécies dos isolados de Trichoderma spp. efetivas como indutores de resistência.

\section{Material e Métodos}

Os experimentos foram realizados no Laboratório de Bioquímica Fitopatológica do Instituto Biológico, São Paulo, SP, de janeiro de 2009 a fevereiro de 2011. Foram utilizadas sementes de pepino híbrido 'Safira' (Sakata Seed Sudamerica Ltda., Bragança Paulista, SP.), cultivadas em substratos comerciais Plantmax Hortaliças HT, (Eucatex Agro, Botucatu, SP) e Tropstrato Hortaliça 1, (VidaVerde, Mogi Mirim, SP) e mantidas em casa de vegetação, onde foram irrigadas por microaspersão automática duas vezes ao dia.

Para avaliar a capacidade de 60 isolados monospóricos de Trichoderma spp., da Coleção de Culturas do Laboratório de Bioquímica Fitopatológica, do Instituto Biológico, São Paulo, SP, na promoção de crescimento de plantas de pepino, foram preparados inicialmente os inóculos de Trichoderma spp. Para isto, dois discos de $9 \mathrm{~mm}$ de diâmetro de meio de cultura batata-dextrose-ágar (BDA), com as estruturas propagativas dos isolados, foram transferidos assepticamente para sacos de plástico que continham $30 \mathrm{~g}$ de arroz e $30 \mathrm{~mL}$ de água destilada previamente esterilizados. A seguir, foram incubados em câmara $\mathrm{BOD}$ a $25^{\circ} \mathrm{C}$, com fotoperíodo de 12 horas, por uma semana. Após esse período, os isolados de Trichoderma spp. foram introduzidos, separadamente, no substrato comercial Plantmax Hortaliças HT, pela adição de arroz colonizado a $2 \%$ (peso:volume). O substrato Plantmax HT foi infestado, separadamente, por meio da adição de $30 \mathrm{~g}$ de arroz colonizado pelos isolados de Trichoderma spp. (em média $2,4 \times 10^{9} \mathrm{UFC} \mathrm{g}^{-1}$ ) a $1.500 \mathrm{~mL}$ de substrato e $30 \mathrm{~mL}$ de água destilada. No tratamento controle, apenas arroz comercial esterilizado foi adicionado ao substrato. A mistura foi incubada por uma semana à temperatura ambiente e, em seguida, as sementes foram semeadas no substrato infestado.

O produto Trichodermil SC (Itaforte BioProdutos, Itapetininga, SP), formulado com Trichoderma harzianum (IT 13/06), concentração mínima de $2 \times 10^{12} \mathrm{~L}^{-1}$ de conídios viáveis, foi aplicado ao substrato conforme indicações do fabricante. Alíquotas de um mililitro de suspensão aquosa do produto à concentração de $0,1 \%(\mathrm{v} / \mathrm{v})$ foram adicionadas a cada $250 \mathrm{~mL}$ de substrato.

As mudas foram mantidas em casa de vegetação até 21 dias de idade, quando a parte aérea das plantas foi seca em estufa a $65-70^{\circ} \mathrm{C}$ até obtenção de massa constante.

Pesq. agropec. bras., Brasília, v.46, n.12, p.1609-1618, dez. 2011 
Os experimentos foram conduzidos em delineamento inteiramente casualizado, com 25 repetições, e cada repetição foi constituída de uma planta; avaliou-se a massa de matéria seca da parte aérea das plantas de pepino (MMS). A massa do sistema radicular não foi avaliada, em razão do grande número de isolados de Trichoderma spp., testados nos experimentos de promoção de crescimento de pepino. Optou-se pela medida da parte aérea, que reflete o bom desenvolvimento do sistema radicular (Björkman et al., 1998).

Os 60 isolados foram divididos aleatoriamente em dois grupos de 30 e avaliados em dois experimentos por período, repetidos três vezes, no total de seis experimentos, com cinco repetições de cinco plantas cada. Os primeiros dois experimentos foram realizados em janeiro e fevereiro de 2009, para cada grupo de 30 isolados. O segundo grupo de dois experimentos foi conduzido em julho e agosto de 2009, e o terceiro em novembro e dezembro de 2009. Nos experimentos, as plantas foram irrigadas por microaspersão automática, duas vezes ao dia, por 5 a $7 \mathrm{~min}$, durante o inverno e verão, respectivamente, e mantidas em casa de vegetação à temperatura mínima média de $14,4^{\circ} \mathrm{C}$ e máxima de $30,8^{\circ} \mathrm{C}$, de acordo com a época do ano em que os experimentos foram realizados. $\mathrm{O}$ efeito do Trichodermil na promoção de crescimento foi avaliado no experimento realizado em dezembro de 2009.

Para o experimento de indução de resistência sistêmica à antracnose em pepineiro, foram utilizados 19 isolados de Trichoderma spp., que aumentaram significativamente a MMS em pelo menos um dos experimentos de promoção de crescimento realizados. Os grãos de arroz colonizados por Trichoderma spp., preparados conforme metodologia já descrita, foram introduzidos no substrato de crescimento Tropstrato Hortaliça 1 a 2\% (peso:volume), com plantas de pepino com 14 dias de idade. A concentração de Trichoderma spp. utilizada no experimento foi determinada pela quantificação do número de conídios, por meio de diluição seriada de amostras de $1 \mathrm{~g}$ de arroz colonizado, com cada um dos isolados, em $9 \mathrm{~mL}$ de solução salina a $0,9 \%$, e contagem subsequente dos conídios em microscópio ótico. Foram utilizadas nos experimentos concentrações de 9 a $71 \times 10^{8}$ de conídios por grama de arroz colonizado. Como controle, foi inserido no substrato o arroz comercial sem Trichoderma spp.

Apóssete dias, as primeiras esegundas folhas verdadeiras das plantas foram infectadas por aspersão, até o ponto de escorrimento, com $5 \mathrm{~mL}$ de suspensão de esporos de C. lagenarium, por planta, à concentração de $1 \times 10^{5} \mathrm{~mL}^{-1}$ de conídios. A suspensão foi preparada a partir da cultura do patógeno em meio aveia, mantida por cinco dias a $25^{\circ} \mathrm{C}$ e em fotoperíodo de 12 horas. As plantas infectadas foram mantidas por 72 horas em câmara de crescimento a $\pm 24^{\circ} \mathrm{C}$, com umidade relativa (UR) superior a $90 \%$, em fotoperíodo de 12 horas e, em seguida, permaneceram na mesma câmara, sem umidificação adicional até o aparecimento dos sintomas. Empregou-se o delineamento experimental inteiramente casualizado, tendo-se utilizado dez plantas por tratamento. A severidade da antracnose foi avaliada nove dias após a inoculação do patógeno, pela contagem do número de lesões por folha em cada planta, de acordo com Kuć \& Richmond (1977). A proteção foi quantificada como redução da severidade da doença e expressa como percentagem do controle.

A concentração e a viabilidade de conídios de Trichoderma spp. e do Trichodermil, utilizados no experimento de indução de resistência, foram determinadas ao microscópio óptico (250x), com auxílio da câmara de Neubauer. Foram avaliados 100 conídios por repetição (quatro repetições por tratamento), entre germinados e não germinados, presentes na suspensão 12 horas após o plaqueamento em meio BDA.

Para avaliar o efeito do intervalo de tempo entre a infestação com Trichoderma sp. e a inoculação de C. lagenarium nas plantas, na redução da severidade de doença, utilizou-se o isolado IB 31/06. Plantas de pepino com 14 dias de idade foram tratadas com esse isolado de Trichoderma, introduzido diretamente no substrato de crescimento, conforme metodologia anterior, aos 3, 7 ou 14 dias antes da inoculação. A inoculação de $C$. lagenarium $\left(1 \times 10^{5} \mathrm{~mL}^{-1}\right.$ de conídios) foi feita por meio da aspersão de $5 \mathrm{~mL}$ de suspensão sobre as folhas verdadeiras de pepineiro, por planta. Utilizou-se o delineamento experimental inteiramente casualizado, com dez plantas por tratamento. A severidade da antracnose foi avaliada nove dias após a inoculação do patógeno, conforme Kuć \& Richmond (1977).

Para a quantificação da atividade da peroxidase por miligrama de proteína total foram obtidos os extratos foliares de plantas de pepino, após a realização dos tratamentos por: pulverização de água, aos 7 e 14 dias antes da extração (controle 7 dias e controle 14 dias); tratamento apenas com Trichoderma sp. IB 31/06, aos sete dias (IB 31/06 7 dias) e aos 14 dias (IB 31/06 14 dias), antes da extração; tratamento com Trichoderma sp., aos 7 dias antes da inoculação de $C$. lagenarium (IB 31/06 + C. lagenarium); e inoculação apenas do 
patógeno (C. lagenarium), aos 7 dias antes da extração. As extrações - três por tratamento - foram realizadas em amostras de $1 \mathrm{~g}$ de folhas, conforme Irving \& Kuć (1990). A quantificação de proteínas nos extratos vegetais foi realizada pelo método de Bradford (1976). A atividade da enzima peroxidase de cada extrato vegetal foi determinada a $30^{\circ} \mathrm{C}$, em espectrofotômetro a $470 \mathrm{~nm}$, pela medida da conversão do guaiacol em tetraguaiacol na presença de peróxido de hidrogênio (Lusso \& Pascholati, 1999). Após três determinações para cada extrato foliar, foi realizado o cálculo da diferença entre a absorbância final e a inicial, e a atividade de peroxidase foi expressa como atividade específica em unidades de absorbância por minuto por miligrama de proteína.

Os 19 isolados de Trichoderma spp., previamente selecionados nos experimentos de promoção de crescimento e avaliados nos experimentos de indução de resistência, foram submetidos ao sequenciamento gênico para a identificação das espécies. A extração de DNA foi realizada de acordo com Murray \& Thompson (1980) e, para a reação em cadeia da polimerase (PCR), foram utilizados os pares de iniciadores ITS 1 (5' TCCGTWGGTGAACCWGC 3') e ITS 4 (5' TCCTCCGCTTATTGATATGC 3'), que amplificam a região espaçadora entre os genes ribossomais $18 \mathrm{~S}$ e 26S (White et al., 1990). Os fragmentos de DNA amplificados foram purificados e submetidos à reação de sequenciamento com o reagente Big Dye Terminator 3.1 (Applied Biosystems, Foster City, CA, EUA), pelo método de terminação de cadeia (Sanger et al., 1977), e analisados em sequenciador automático ABI 377 (Applied Biosystems, Foster City, CA, EUA). As sequências de nucleotídeos foram submetidas aos programas TrichoBLAST e TrichOKEY, disponíveis em International Subcommission on Trichoderma and Hypocrea Taxonomy (2011), que permitem realizar a identificação molecular de fungos do gênero Trichoderma, por meio da comparação com sequências de espécies "vouchers" (Druzhinina et al., 2005; Kopchinskiy et al., 2005; Nagy et al., 2007).

Todos os experimentos foram repetidos três vezes. Os dados obtidos foram submetidos à análise de variância e comparados pelo teste de Tukey, a $1 \%$ de probabilidade, com o Assistat, versão 7.5 Beta (Silva \& Azevedo, 2006).

\section{Resultados e Discussão}

No primeiro grupo de experimentos, realizados em janeiro e fevereiro de 2009, as linhagens que proporcio- naram maior aumento na massa de matéria seca (MMS) e diferiram significativamente dos respectivos controles foram: IB 15/06, IB 22/08, IB 31/06, IB 32/06, IB 34/08, IB 38/11 e IB 47/05, com valores entre 47,83 e $86,90 \%$ (Tabelas 1 e 2). Na segunda repetição dos experimentos, realizada em julho e agosto de 2009, o maior aumento na MMS foi obtido com os isolados: IB 01/03, IB 01/13, IB 04/08, IB 07/09, IB 17/07, IB 28/07, IB 31/06, IB 34/08 e IB 42/03, com valores entre 52,88 e $100 \%$. Na terceira repetição dos experimentos, realizada em novembro e dezembro de 2009, os isolados que mais aumentaram a MMS das plantas, tendo diferido dos respectivos controles, foram: IB 01/03, IB 15/06, IB 18/13, IB 34/01, IB 37/01, IB 46/11 e IB 48/23, com incrementos entre 43,37 e $89,83 \%$. Além disso, o produto Trichodermil, formulado com a linhagem IT 13/06, promoveu aumento de 74,58\% na MMS da parte aérea das plantas de pepino. Com a realização dos experimentos, foram observados diferentes incrementos na MMS das plantas de pepino, em cada grupo de experimentos, e as plantas tratadas com os isolados IB 01/03, IB 15/06, IB 31/06 e IB 34/08 apresentaram aumentos significativos da MMS em dois dos três grupos de experimentos realizados. A variabilidade do efeito dos isolados no crescimento das plantas pode estar relacionada à realização dos experimentos em diferentes períodos do ano. Segundo Akrami et al. (2011), vários fatores podem interferir na eficiência dos agentes benéficos, entre eles os abióticos, principalmente a temperatura e a umidade, que são consideradas cruciais para garantir o bom desempenho dos isolados de Trichoderma spp.

Segundo Brotman et al. (2010), espécies de Trichoderma spp. podem promover aumentos de até 300\% no crescimento de plantas. Os resultados do presente trabalho corroboram os de Yedidia et al. (2001), que avaliaram o efeito de T. harzianum sobre o crescimento de pepineiro e observaram aumento significativo de $80 \%$ na MMS da parte aérea das plantas. No experimento de indução de resistência em pepineiro, todos os isolados de Trichoderma, introduzidos no substrato de crescimento sete dias antes da inoculação de $C$. lagenarium nas folhas das plantas, reduziram significativamente os sintomas da doença e conferiram proteção sistêmica contra a antracnose de 56,36 a 88,39\% (Tabela 3). Os isolados que mais se destacaram foram: IB 01/03, IB 01/13, IB 07/09, IB 31/06, IB 34/08 e IB 37/01, que conferiram proteção acima de $83 \%$. Além disso, plantas tratadas com o produto Trichodermil (IT 13/06) também apresentaram redução 
significativa dos sintomas de antracnose, em comparação ao controle não tratado.

Os isolados de Trichoderma spp. colonizam a epiderme e as células do córtex das raízes e, consequentemente, ativam vias de sinalização, desencadeando respostas de defesa nas plantas (Brotman et al., 2010). Em experimento realizado em pepineiro, tratado com $T$. asperellum, os sintomas da doença causada por $P$. syringae pv. lachrymans foram reduzidos em $80 \%$, em comparação às folhas não tratadas. De acordo com os autores, a separação espacial entre o tratamento com Trichoderma no solo e a inoculação do patógeno nas folhas, que resultou na redução da mancha-angular nas folhas, evidenciou a ocorrência de indução de resistência sistêmica nesse patossistema (Yedidia et al., 2003). Segundo Segarra et al. (2009), em estudos realizados em Arabdopsis thaliana, com o isolado T-34 de T. asperellum para induzir resistência contra $P$. syringae pv. tomato, foi observado que as plantas tratadas apresentaram menos sintomas de doença do que as plantas controle.

Os conídios de Trichoderma spp., presentes nos grãos de arroz, foram quantificados no início dos experimentos de indução de resistência. Observouse que, entre os 19 isolados avaliados, a quantidade

Tabela 1. Massa de matéria seca de plantas de pepino, tratadas com 30 isolados de Trichoderma spp., avaliada nos experimentos realizados em janeiro, julho e novembro de $2009^{(1)}$.

\begin{tabular}{|c|c|c|c|c|c|c|}
\hline \multirow[t]{2}{*}{ Tratamento } & \multicolumn{2}{|c|}{ Janeiro } & \multicolumn{2}{|l|}{ Julho } & \multicolumn{2}{|c|}{ Novembro } \\
\hline & $\begin{array}{c}\text { Massa de matéria seca } \\
(\mathrm{g})\end{array}$ & $\begin{array}{c}\text { Crescimento }^{(2)} \\
(\%)\end{array}$ & $\begin{array}{l}\text { Massa de matéria seca } \\
(\mathrm{g})\end{array}$ & $\begin{array}{c}\text { Crescimento }^{(2)} \\
(\%)\end{array}$ & $\begin{array}{l}\text { Massa de matéria seca } \\
(\mathrm{g})\end{array}$ & $\begin{array}{c}\text { Crescimento }^{(2)} \\
(\%)\end{array}$ \\
\hline Controle & $0,092 \pm 0,004 \mathrm{ef}$ & - & $0,076 \pm 0,007 \mathrm{~d}$ & - & $0,083 \pm 0,003 \mathrm{~cd}$ & - \\
\hline IB $01 / 05$ & $0,116 \pm 0,013$ abcdef & 26,08 & $0,093 \pm 0,006 \mathrm{bcd}$ & 22,36 & $0,092 \pm 0,003 \mathrm{bcd}$ & 10,85 \\
\hline IB 01/13 & $0,130 \pm 0,007 \mathrm{abcde}$ & 41,30 & $0,123 \pm 0,006 \mathrm{ab}$ & 61,84 & $0,085 \pm 0,003 \mathrm{bcd}$ & 2,40 \\
\hline IB 04/05 & $0,104 \pm 0,004 \mathrm{cdef}$ & 13,05 & $0,108 \pm 0,009 \mathrm{bcd}$ & 42,11 & $0,083 \pm 0,007 \mathrm{~cd}$ & 0,00 \\
\hline IB 04/08 & $0,115 \pm 0,003$ abcdef & 25,00 & $0,117 \pm 0,003 \mathrm{abc}$ & 53,94 & $0,077 \pm 0,001 d$ & $-7,22$ \\
\hline IB 04/09 & $0,094 \pm 0,010 \mathrm{def}$ & 2,17 & $0,109 \pm 0,013 \mathrm{bcd}$ & 43,42 & $0,082 \pm 0,004 \mathrm{~cd}$ & $-1,20$ \\
\hline IB 08/04 & $0,130 \pm 0,005$ abcde & 41,30 & $0,105 \pm 0,007 \mathrm{bcd}$ & 38,16 & 0,098 $\pm 0,006 \mathrm{abcd}$ & 18,08 \\
\hline IB 09/02 & $0,116 \pm 0,007 \mathrm{abcdef}$ & 26,08 & $0,114 \pm 0,005 \mathrm{abcd}$ & 50,00 & $0,093 \pm 0,008 \mathrm{bcd}$ & 12,05 \\
\hline IB $10 / 05$ & $0,125 \pm 0,011$ abcdef & 35,87 & $0,104 \pm 0,006 \mathrm{bcd}$ & 36,84 & $0,090 \pm 0,007 \mathrm{bcd}$ & 8,43 \\
\hline IB 11/09 & $0,111 \pm 0,007$ abcedf & 20,66 & $0,076 \pm 0,004 d$ & 0,00 & $0,090 \pm 0,002 \mathrm{bcd}$ & 8,43 \\
\hline IB 11/12 & $0,114 \pm 0,004$ abcdef & 23,91 & $0,105 \pm 0,006 \mathrm{bcd}$ & 38,16 & $0,084 \pm 0,005 \mathrm{~cd}$ & 1,20 \\
\hline IB 13/08 & $0,099 \pm 0,006 \mathrm{cdef}$ & 7,61 & $0,100 \pm 0,003 \mathrm{bcd}$ & 31,57 & $0,092 \pm 0,011 \mathrm{bcd}$ & 10,85 \\
\hline IB 14/04 & $0,099 \pm 0,003 \mathrm{cdef}$ & 7,61 & $0,094 \pm 0,003 \mathrm{bcd}$ & 23,68 & $0,085 \pm 0,005 \mathrm{bcd}$ & 2,40 \\
\hline IB 15/06 & $0,138 \pm 0,006 \mathrm{abc}$ & 50,00 & $0,090 \pm 0,009 \mathrm{bcd}$ & 18,42 & $0,119 \pm 0,009 \mathrm{ab}$ & 43,37 \\
\hline IB $17 / 07$ & $0,116 \pm 0,011$ abcdef & 26,08 & $0,120 \pm 0,007 \mathrm{abc}$ & 57,89 & $0,085 \pm 0,003 \mathrm{bcd}$ & 2,40 \\
\hline IB 18/03 & $0,113 \pm 0,008$ abcdef & 22,83 & $0,075 \pm 0,003 \mathrm{~d}$ & $-1,32$ & $0,085 \pm 0,004 \mathrm{~cd}$ & 2,40 \\
\hline IB $18 / 22$ & $0,104 \pm 0,008 \mathrm{cdef}$ & 13,05 & $0,114 \pm 0,009 \mathrm{abcd}$ & 50,00 & $0,095 \pm 0,002 \mathrm{bcd}$ & 14,45 \\
\hline IB 20/02 & $0,095 \pm 0,003 \mathrm{cdef}$ & 3,27 & $0,105 \pm 0,005 \mathrm{bcd}$ & 38,16 & $0,081 \pm 0,003 \mathrm{~d}$ & $-2,40$ \\
\hline IB 22/08 & $0,149 \pm 0,010 \mathrm{ab}$ & 61,96 & $0,106 \pm 0,008 \mathrm{bcd}$ & 39,48 & $0,090 \pm 0,004 \mathrm{bcd}$ & 8,43 \\
\hline IB 26/06 & $0,086 \pm 0,002 f$ & $-6,52$ & $0,094 \pm 0,007 \mathrm{bcd}$ & 23,68 & $0,097 \pm 0,003 \mathrm{abcd}$ & 16,87 \\
\hline IB 26/07 & $0,106 \pm 0,004$ bcdef & 15,22 & $0,081 \pm 0,006 \mathrm{~cd}$ & 6,57 & $0,099 \pm 0,007 \mathrm{abcd}$ & 19,27 \\
\hline IB 31/06 & $0,152 \pm 0,008 \mathrm{a}$ & 65,22 & $0,152 \pm 0,008 \mathrm{a}$ & 100,00 & $0,086 \pm 0,096 \mathrm{bcd}$ & 3,61 \\
\hline IB 37/01 & $0,099 \pm 0,006 \mathrm{cdef}$ & 7,61 & $0,097 \pm 0,008 \mathrm{bcd}$ & 27,64 & $0,131 \pm 0,014 \mathrm{a}$ & 57,83 \\
\hline IB 37/05 & $0,097 \pm 0,008 \mathrm{cdef}$ & 5,44 & $0,110 \pm 0,011 \mathrm{bcd}$ & 44,73 & $0,101 \pm 0,006 a b c d$ & 21,68 \\
\hline IB 38/11 & $0,136 \pm 0,015 \mathrm{abcd}$ & 47,83 & $0,088 \pm 0,005 \mathrm{bcd}$ & 15,79 & $0,080 \pm 0,004 d$ & $-3,61$ \\
\hline IB $42 / 15$ & $0,113 \pm 0,005 \mathrm{abcdef}$ & 22,83 & $0,113 \pm 0,006 a b c d$ & 48,68 & $0,115 \pm 0,004 \mathrm{abc}$ & 38,55 \\
\hline IB 46/10 & $0,104 \pm 0,005 \mathrm{cdef}$ & 13,05 & $0,112 \pm 0,008 \mathrm{bcd}$ & 47,36 & $0,087 \pm 0,005 \mathrm{bcd}$ & 4,82 \\
\hline IB 47/05 & $0,150 \pm 0,009 a$ & 63,04 & $0,106 \pm 0,007 \mathrm{bcd}$ & 39,48 & 0,098 $\pm 0,002 \mathrm{abcd}$ & 18,08 \\
\hline IB 50/01 & $0,129 \pm 0,011 \mathrm{abcdef}$ & 40,22 & $0,089 \pm 0,005 \mathrm{bcd}$ & 17,11 & $0,090 \pm 0,005 \mathrm{bcd}$ & 8,43 \\
\hline IB 50/07 & $0,092 \pm 0,004 \mathrm{ef}$ & 0,00 & $0,083 \pm 0,004 \mathrm{bcd}$ & 9,21 & $0,097 \pm 0,009 \mathrm{abcd}$ & 16,87 \\
\hline IB 50/20 & $0,120 \pm 0,005$ abcdef & 30,44 & $0,091 \pm 0,003 \mathrm{bcd}$ & 19,73 & $0,091 \pm 0,006 \mathrm{bcd}$ & 9,63 \\
\hline $\mathrm{CV}(\%)$ & 15,30 & & 15,95 & & $15,0^{7}$ & \\
\hline
\end{tabular}

${ }^{(1)}$ Médias \pm erro-padrão seguidas de letras iguais, nas colunas, não diferem, entre si, pelo teste de Tukey, a 1\% de probabilidade. Média de 25 repetições. ${ }^{(2)}$ Aumento de crescimento, determinado em relação ao controle, calculado como acréscimo na massa de matéria seca da parte aérea das plantas de pepino e expresso como percentagem. 
de conídios por grama de arroz colonizado variou de $1,4 \times 10^{9}$ (IB 07/09 e IB 15/06) a $5,3 \times 10^{9}$ (IB 34/08), enquanto o número médio de conídios por mililitro do produto comercial foi de $3,5 \times 10^{9}$ (IT 13/06). A percentagem de conídios germinados variou entre $46,9 \%$ (IB 37/01) e 89,9\% (IB 31/06), o que confirma a viabilidade dos conídios presentes no arroz colonizado.
Não foi observada correlação direta entre a viabilidade dos isolados e a capacidade de controlar a antracnose.

Constatou-se que o isolado IB 31/06 conferiu proteção significativa contra a antracnose, em todos os intervalos de tempo avaliados (Tabela 4). É importante ressaltar que a aplicação do isolado, apenas três dias antes da inoculação do patógeno nas plantas, reduziu

Tabela 2. Massa de matéria seca de plantas de pepino, tratadas com 30 isolados de Trichoderma spp., avaliada nos experimentos realizados em fevereiro, agosto e dezembro de $2009^{(1)}$.

\begin{tabular}{|c|c|c|c|c|c|c|}
\hline \multirow[t]{2}{*}{ Tratamento } & \multicolumn{2}{|c|}{ Fevereiro } & \multicolumn{2}{|c|}{ Agosto } & \multicolumn{2}{|c|}{ Dezembro } \\
\hline & $\begin{array}{c}\text { Massa de matéria } \\
\text { seca }(\mathrm{g})\end{array}$ & $\begin{array}{c}\text { Crescimento }^{(2)} \\
(\%)\end{array}$ & $\begin{array}{l}\text { Massa de matéria } \\
\text { seca }(\mathrm{g})\end{array}$ & $\begin{array}{c}\text { Crescimento }^{(2)} \\
(\%)\end{array}$ & $\begin{array}{c}\text { Massa de matéria } \\
\operatorname{seca}(\mathrm{g})\end{array}$ & $\begin{array}{c}\text { Crescimento }^{(2)} \\
(\%)\end{array}$ \\
\hline Controle & $0,084 \pm 0,01 \mathrm{c}$ & - & $0,104 \pm 0,006 \mathrm{fgh}$ & - & $0,059 \pm 0,004 \mathrm{e}$ & - \\
\hline IB 01/03 & $0,090 \pm 0,005 \mathrm{c}$ & 7,14 & $0,194 \pm 0,003 a$ & 86,54 & $0,095 \pm 0,005 \mathrm{abcd}$ & 61,01 \\
\hline IB 02/03 & $0,107 \pm 0,002 \mathrm{bc}$ & 27,38 & $0,110 \pm 0,007$ defgh & 5,76 & $0,093 \pm 0,003 \mathrm{abcde}$ & 57,62 \\
\hline IB 04/04 & $0,094 \pm 0,003 \mathrm{c}$ & 11,91 & $0,107 \pm 0,13$ defgh & 2,88 & $0,080 \pm 0,004 \mathrm{abcde}$ & 35,59 \\
\hline IB 06/04 & $0,100 \pm 0,003 \mathrm{c}$ & 19,04 & $0,146 \pm 0,005$ abcdef & 40,38 & $0,090 \pm 0,008 \mathrm{abcde}$ & 52,55 \\
\hline IB 07/09 & $0,090 \pm 0,004 \mathrm{c}$ & 7,14 & $0,160 \pm 0,005 \mathrm{abcd}$ & 53,85 & $0,092 \pm 0,005 \mathrm{abcde}$ & 55,93 \\
\hline IB 18/13 & $0,094 \pm 0,005 \mathrm{c}$ & 11,91 & $0,145 \pm 0,008 \mathrm{abcdef}$ & 39,43 & $0,107 \pm 0,004 \mathrm{ab}$ & 81,35 \\
\hline IB 19/17 & $0,085 \pm 0,003^{\mathrm{c}}$ & 1,20 & $0,112 \pm 0,007$ defgh & 7,69 & $0,074 \pm 0,004$ bcde & 25,42 \\
\hline IB 19/19 & $0,095 \pm 0,004 \mathrm{c}$ & 13,09 & $0,105 \pm 0,017 \mathrm{efgh}$ & 0,96 & $0,060 \pm 0,002 \mathrm{de}$ & 1,69 \\
\hline IB 22/03 & $0,101 \pm 0,004 \mathrm{c}$ & 20,24 & $0,150 \pm 0,009 \mathrm{abcdef}$ & 44,24 & $0,083 \pm 0,005$ abcde & 40,68 \\
\hline IB 26/10 & $0,099 \pm 0,004 \mathrm{c}$ & 17,85 & $0,157 \pm 0,007 \mathrm{abcdef}$ & 50,96 & $0,079 \pm 0,007 \mathrm{abcde}$ & 33,89 \\
\hline IB 26/11 & $0,092 \pm 0,004 \mathrm{c}$ & 9,53 & $0,074 \pm 0,008 \mathrm{~h}$ & $-28,84$ & $0,087 \pm 0,007$ abcde & 47,45 \\
\hline IB 26/12 & $0,090 \pm 0,004 \mathrm{c}$ & 7,14 & $0,081 \pm 0,003 \mathrm{gh}$ & $-22,12$ & $0,074 \pm 0,005 \mathrm{bcde}$ & 25,42 \\
\hline IB 27/10 & $0,097 \pm 0,003 \mathrm{c}$ & 15,48 & $0,119 \pm 0,009$ defgh & 14,43 & $0,081 \pm 0,006 \mathrm{abcde}$ & 37,28 \\
\hline IB 28/06 & $0,102 \pm 0,003 \mathrm{bc}$ & 21,43 & $0,144 \pm 0,011 \mathrm{abcdef}$ & 38,46 & $0,081 \pm 0,011 \mathrm{abcde}$ & 37,28 \\
\hline IB 28/07 & $0,099 \pm 0,008 \mathrm{c}$ & 17,85 & $0,159 \pm 0,011$ abcde & 52,88 & $0,083 \pm 0,004 \mathrm{abcde}$ & 40,68 \\
\hline IB 28/14 & $0,112 \pm 0,014 \mathrm{bc}$ & 33,33 & $0,103 \pm 0,003$ fgh & $-0,96$ & $0,079 \pm 0,002 \mathrm{abcde}$ & 33,89 \\
\hline IB 32/06 & $0,135 \pm 0,005 \mathrm{ab}$ & 60,71 & $0,139 \pm 0,005$ abcdef & 33,65 & $0,074 \pm 0,007 \mathrm{bcde}$ & 25,42 \\
\hline IB 34/01 & $0,092 \pm 0,003 \mathrm{c}$ & 9,53 & $0,128 \pm 0,006 \mathrm{cdefgh}$ & 23,07 & $0,095 \pm 0,006 a b c d$ & 61,01 \\
\hline IB 34/08 & $0,157 \pm 0,006 \mathrm{a}$ & 86,90 & $0,176 \pm 0,009 \mathrm{abc}$ & 69,23 & $0,068 \pm 0,003$ cde & 15,25 \\
\hline IB 34/10 & $0,117 \pm 0,011 \mathrm{bc}$ & 39,28 & $0,156 \pm 0,007 \mathrm{abcdef}$ & 50,00 & $0,094 \pm 0,010 \mathrm{abcde}$ & 59,32 \\
\hline IB 40/12 & $0,101 \pm 0,006 \mathrm{c}$ & 20,24 & $0,112 \pm 0,007 \mathrm{defgh}$ & 7,69 & $0,086 \pm 0,003 \mathrm{abcde}$ & 45,76 \\
\hline IB 42/03 & $0,110 \pm 0,002 b c$ & 30,96 & $0,183 \pm 0,016 \mathrm{ab}$ & 75,96 & $0,087 \pm 0,006 \mathrm{abcde}$ & 47,45 \\
\hline IB 46/08 & $0,100 \pm 0,008 \mathrm{c}$ & 19,04 & $0,133 \pm 0,007 \mathrm{bcdefg}$ & 27,88 & $0,063 \pm 0,005 \mathrm{de}$ & 6,78 \\
\hline IB 46/11 & $0,100 \pm 0 \mathrm{c}$ & 19,04 & $0,141 \pm 0,010$ abcdef & 35,57 & $0,102 \pm 0,006 \mathrm{abc}$ & 72,88 \\
\hline IB 47/16 & $0,102 \pm 0,005 \mathrm{c}$ & 21,43 & $0,126 \pm 0,005 \mathrm{cdefgh}$ & 21,15 & $0,077 \pm 0,005 \mathrm{abcde}$ & 30,51 \\
\hline IB 48/06 & $0,091 \pm 0,003 \mathrm{c}$ & 8,33 & $0,120 \pm 0,013 \mathrm{defgh}$ & 15,38 & $0,081 \pm 0,008 \mathrm{abcde}$ & 37,28 \\
\hline IB 48/09 & $0,100 \pm 0,006 \mathrm{c}$ & 19,04 & $0,151 \pm 0,009$ abcdef & 45,19 & $0,068 \pm 0,003$ cde & 15,25 \\
\hline IB $48 / 23$ & $0,093 \pm 0,004 \mathrm{c}$ & 10,72 & $0,119 \pm 0,008$ defgh & 14,43 & $0,112 \pm 0,017^{\mathrm{a}}$ & 89,83 \\
\hline IB 49/08 & $0,104 \pm 0,002 \mathrm{bc}$ & 23,80 & $0,113 \pm 0,006 \mathrm{defgh}$ & 8,65 & $0,085 \pm 0,004 \mathrm{abcde}$ & 44,07 \\
\hline IB 49/16 & $0,087 \pm 0,005 \mathrm{c}$ & 3,57 & $0,106 \pm 0,004 \mathrm{defgh}$ & 1,93 & $0,083 \pm 0,004 \mathrm{abcde}$ & 40,68 \\
\hline Trichodermil & - & - & - & - & $0,103 \pm 0,004 \mathrm{abc}$ & 74,58 \\
\hline $\mathrm{CV}(\%)$ & \multicolumn{2}{|c|}{13,29} & \multicolumn{2}{|c|}{17,20} & \multicolumn{2}{|c|}{17,36} \\
\hline
\end{tabular}

${ }^{(1)}$ Médias \pm erro-padrão seguidas de letras iguais não diferem, pelo teste de Tukey a $1 \%$ de probabilidade. Média de 25 repetições. ${ }^{(2)}$ Aumento de crescimento, determinado em relação ao controle, calculado como acréscimo na massa de matéria seca da parte aérea das plantas de pepino e expresso como percentagem. 
significativamente os sintomas da antracnose. Isso indica que o tratamento prévio com Trichoderma pode controlar em poucos dias a doença, embora se tenha observado um aumento considerável na proteção da planta do terceiro para o sétimo dia.

Koike et al. (2001) também observaram um rápido efeito de Trichoderma em pepineiro, que induziu lignificação, produção de superóxido e proteção contra Colletotrichum orbiculare e P. syringae pv. lachrymans de 59 e $52 \%$, respectivamente, quando aplicado nas raízes um dia antes da inoculação dos patógenos nas folhas. Yedidia et al. (2003) também constataram diminuição de $50 \%$ do diâmetro das lesões causadas por $P$. syringae pv. lachrymans em pepineiro, em decorrência do tratamento das raízes com $T$. asperellum dois dias antes da inoculação do patógeno. De acordo com Perazzoli et al. (2008), o tratamento de videira com T. harzianum, realizado um dia antes da inoculação de Plasmopara viticola para o controle do míldio, reduziu as lesões da doença em 38\%. Entretanto, quando T. harzianum foi aplicado aos 7 ou 14 dias antes da

Tabela 3. Severidade de antracnose em pepineiro, em substrato infestado com isolados de Trichoderma spp. aos sete dias antes da inoculação de Colletotrichum lagenarium ${ }^{(1)}$.

\begin{tabular}{lcc}
\hline Tratamento & $\begin{array}{c}\text { Número médio de } \\
\text { lesões por planta }\end{array}$ & $\begin{array}{c}\text { Redução da severidade } \\
(\%)^{(2)}\end{array}$ \\
\hline Controle & $49,95 \pm 3,66 \mathrm{a}$ & - \\
IB 18/13 & $21,80 \pm 3,65 \mathrm{~b}$ & 56,36 \\
IB 47/05 & $21,75 \pm 3,74 \mathrm{~b}$ & 56,46 \\
IB 28/07 & $18,45 \pm 3,66 \mathrm{bc}$ & 63,07 \\
IB 42/03 & $16,15 \pm 3,20 \mathrm{bc}$ & 67,67 \\
IB 34/01 & $14,89 \pm 1,72 \mathrm{bc}$ & 70,20 \\
IB 04/08 & $14,40 \pm 4,58 \mathrm{bc}$ & 71,18 \\
IB 17/07 & $14,35 \pm 1,86 \mathrm{bc}$ & 71,28 \\
IB 48/23 & $12,50 \pm 4,28 \mathrm{bc}$ & 74,98 \\
IB 15/06 & $12,15 \pm 1,26 \mathrm{bc}$ & 75,68 \\
IB 46/11 & $11,50 \pm 1,91 \mathrm{bc}$ & 76,98 \\
IB 32/06 & $06,60 \pm 2,21 \mathrm{bc}$ & 80,79 \\
IB 22/08 & $09,05 \pm 1,79 \mathrm{bc}$ & 81,89 \\
IB 38/11 & $08,90 \pm 0,93 \mathrm{bc}$ & 82,19 \\
Trichodermil & $08,77 \pm 1,29 \mathrm{bc}$ & 82,44 \\
IB 37/01 & $08,05 \pm 0,74 \mathrm{c}$ & 83,88 \\
IB 01/13 & $07,35 \pm 2,22 \mathrm{c}$ & 85,29 \\
IB 07/09 & $07,06 \pm 1,07 \mathrm{c}$ & 86,41 \\
IB 34/08 & $07,00 \pm 1,60 \mathrm{c}$ & 85,99 \\
IB 01/03 & $06,35 \pm 1,06 \mathrm{c}$ & 87,30 \\
IB 31/06 & $05,80 \pm 1,21 \mathrm{c}$ & 88,39 \\
CV(\%) & 60,24 & \\
\hline
\end{tabular}

${ }^{(1)}$ Médias \pm erro-padrão seguidas de letras iguais, nas colunas, não diferem entre si, pelo teste de Tukey a $1 \%$ de probabilidade. Média de dez repetições. ${ }^{(2)}$ Determinada em relação ao controle. inoculação do patógeno, as reduções foram de apenas 12 e $4 \%$, respectivamente, e diferiram dos resultados observados no presente trabalho.

Não houve diferença significativa, quanto à ativação da enzima peroxidase, entre os tratamentos realizados com o isolado IB 31/06 após 7 ou 14 dias, em comparação ao tratamento controle (Figura 1). Apenas as plantas infectadas com C. lagenarium, previamente tratadas ou não com IB 31/06, apresentaram aumento significativo da atividade enzimática. No entanto, Yedidia et al. (1999) verificaram que o agente de biocontrole $T$. harzianum induz o aumento da atividade dessa enzima em plantas de pepino. De acordo com esses autores, a atividade de peroxidase aumentou após intervalos de tempo inferiores a sete dias, o que pode explicar o resultado obtido no presente trabalho, em que não foi observado aumento da atividade enzimática aos 7 e 14 dias após o tratamento das plantas com IB $31 / 06$.

Dos 19 isolados de Trichoderma spp. que se destacaram como agentes promotores de crescimento e protegeram o pepineiro contra a antracnose, 11 foram identificados como T. harzianum (Tabela 5). Além dessa, foram identificadas, ainda, as espécies: $T$. asperellum (três isolados), T. atroviride (dois isolados), T. strigosum (um isolado), T. longibrachiatum (um isolado), $T$. koningiopsis ou $T$. ovalisporum (um isolado). Os isolados apresentaram similaridade

Tabela 4. Severidade da antracnose em pepineiro, em substrato infestado com o isolado de Trichoderma spp. (IB 31/06) aos 3, 7 ou 14 dias antes da inoculação de Colletotrichum lagenarium ${ }^{(1)}$.

\begin{tabular}{|c|c|c|}
\hline Tratamento & $\begin{array}{l}\text { Número médio de } \\
\text { lesões por planta }\end{array}$ & $\begin{array}{c}\text { Redução da severidade } \\
(\%)^{(2)}\end{array}$ \\
\hline & \multicolumn{2}{|c|}{3 dias } \\
\hline IB $31 / 06$ & $09,75 \pm 1,33 b$ & 49,22 \\
\hline Controle & $19,20 \pm 2,56 \mathrm{a}$ & - \\
\hline \multirow[t]{2}{*}{$\begin{array}{l}\mathrm{CV}(\%) \\
\end{array}$} & \multicolumn{2}{|c|}{44,60} \\
\hline & \multicolumn{2}{|c|}{7 dias } \\
\hline IB $31 / 06$ & $04,20 \pm 0,48 b$ & 69,45 \\
\hline Controle & $13,75 \pm 1,34 \mathrm{a}$ & - \\
\hline \multirow[t]{2}{*}{ CV (\%) } & \multicolumn{2}{|c|}{35,84} \\
\hline & \multicolumn{2}{|c|}{14 dias } \\
\hline IB 31/06 & $04,20 \pm 1,26 b$ & 78,68 \\
\hline Controle & $19,70 \pm 2,13 \mathrm{a}$ & - \\
\hline CV (\%) & \multicolumn{2}{|c|}{46,56} \\
\hline
\end{tabular}

${ }^{(1)}$ Médias \pm erro-padrão seguidas de letras iguais, nas colunas, não diferem entre si pelo teste de Tukey, a 1\% de probabilidade. Média de dez repetições. ${ }^{(2)}$ Redução da severidade determinada em relação ao controle. 


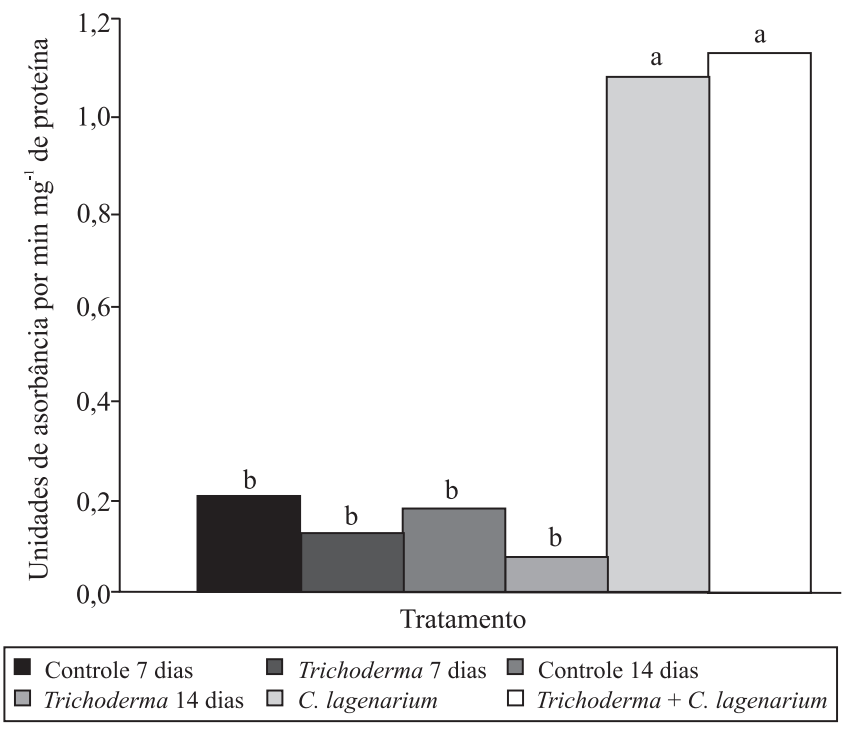

Figura 1. Atividade da peroxidase dos extratos foliares de pepineiro tratados com: água, controle; isolado de Trichoderma spp. IB 31/06, durante 7 e 14 dias; IB 31/06, 7 dias antes da inoculação de Colletotrichum lagenarium; e C. lagenarium. Tratamentos seguidos por letras iguais não diferem entre si, pelo teste de Tukey, a $1 \%$ de probabilidade.

Tabela 5. Espécies de Trichoderma spp., identificadas por sequenciamento gênico da região ITS do DNA ribossômico e pelas sequências de nucleotídeos, nos programas TrichoBLAST e TrichOKEY, por meio da comparação com sequências de espécies "vouchers".

\begin{tabular}{lcc}
\hline Isolado & Espécie & Autores das espécies \\
\hline IB 01/03 & Trichoderma asperellum & Samuels, Lieckfeldt \& Nirenberg, 1999 \\
IB 01/13 & Trichoderma asperellum & Samuels, Lieckfeldt \& Nirenberg, 1999 \\
IB 04/08 & Trichoderma asperellum & Samuels, Lieckfeldt \& Nirenberg, 1999 \\
IB 07/09 & Trichoderma atroviride & Karsten, 1892 \\
IB 15/06 & Trichoderma harzianum & Rifai, 1969, 1991 \\
IB 17/07 & Trichoderma harzianum & Rifai, 1969, 1991 \\
IB 18/13 & Trichoderma atroviride & Karsten, 1892 \\
IB 22/08 & Trichoderma harzianum & Rifai, 1969, 1991 \\
IB 28/07 & Trichoderma strigosum & Bissett, 1991 \\
IB 31/06 & Trichoderma harzianum & Rifai, 1969, 1991 \\
IB 32/06 & Trichoderma harzianum & Rifai, 1969, 1991 \\
IB 34/01 & Trichoderma harzianum & Rifai, 1969, 1991 \\
IB 34/08 & Trichoderma harzianum & Rifai, 1969, 1991 \\
IB 37/01 & Trichoderma longibrachiatum & Bissett, 1984 \\
IB 38/11 & Trichoderma harzianum & Rifai, 1969, 1991 \\
IB 42/03 & Trichoderma harzianum & Rifai, 1969, 1991 \\
IB 46/11 & Trichoderma harzianum & Rifai, 1969, 1991 \\
IB 47/05 & Trichoderma harzianum & Rifai, 1969, 1991 \\
IB 48/23 & Trichoderma koningiopsis ou & Samuels, Suarez \& Evans, 2006; \\
& T. ovalisporum & Samuels \& Schroers, 2004 \\
\hline
\end{tabular}

superior a 98\%, em comparação aos isolados "voucher" das bases de dados, para a região ITS, identificados pelo programa TrichOKEY. O isolado IB 48/23 foi identificado como T. ovalisporum ou T. koningiopsis. De acordo com Druzhinina et al. (2005), essas espécies não são distinguíveis pelo sequenciamento da região ITS, pois possuem sequências idênticas. Entre os isolados caracterizados como T. harzianum (IB 15/06, IB 17/07, IB 22/08, IB 31/06, IB 32/06, IB 34/01, IB 34/08, IB 38/11, IB 42/03, IB 46/11 e IB 47/05), o IB 31/06 se destacou na promoção de crescimento de plantas e na redução das lesões de antracnose em pepineiro. Além deste, os demais dez isolados, caracterizados como T. harzianum, também foram eficientes na proteção contra a antracnose, tendo reduzido a severidade da doença de 56,46 a $85,99 \%$ (IB 47/05 e IB 34/08). No presente trabalho, as espécies T. asperellum (IB 01/03, IB 01/13 e IB 04/08) e T. atroviride (IB 07/09 e IB 18/13) foram também identificadas (Tabela 5). Estes isolados também se destacaram como indutores de resistência contra C. lagenarium e conferiram proteção a pepineiro de 56,36 a $87,30 \%$ (Tabelas 3 ).

\section{Conclusões}

1. Dezenove isolados de Trichoderma spp. e o produto Trichodermil promovem o crescimento em plantas de pepino e induzem resistência à antracnose em pepineiro.

2. As espécies Trichoderma harzianum, T. asperellum, T. atroviride, T. strigosum, T. longibrachiatum, e T. koningiopsis ou T. ovalisporum são eficientes como promotores do crescimento de plantas e como indutores de resistência à antracnose em pepineiro.

\section{Agradecimentos}

À Empresa Itaforte Bioprodutos, pelo auxílio financeiro concedido e pelo fornecimento do produto comercial utilizado neste trabalho.

\section{Referências}

AGRIOS, G.N. Plant pathology. $5^{\text {th }}$ ed. San Diego: Academic, 2004. 952p.

AKRAMI, M.; GOLZARY, H.; AHMADZADEH, M. Evaluation of different combinations of Trichoderma species for controlling Fusarium rot of lentil. African Journal of Biotechnology, v.10, p.2653-2658, 2011. 
BJÖRKMAN, T.; BLANCHARD, L.M.; HARMAN, G.E. Growth enhancement of shrunken-2 (sh2) sweet corn by Trichoderma harzianum 1295-22: effect of environmental stress. Journal of the American Society for Horticultural Science, v.123, p.35-40, 1998.

BRADFORD, M. A rapid and sensitive method for the quantitation of microgram quantities of protein utilizing the principle of protein-dye binding. Analytical Biochemistry, v.72, p.248-254, 1976.

BROTMAN, Y.; GUPTA, K.J.; VITERBO, A. Trichoderma. Current Biology, v.20, p.R390-R391, 2010.

DRUZHININA, I.S.; KOPTCHINSKI, A.G.; KOMOM, M.; BISSET, J.; SZAKACS, G.; KUBICEK, C.P. An oligonucleotide barcode for species identification in Trichoderma and Hypocrea. Fungal Genetics and Biology, v.42, p.813-828, 2005.

HARMAM, G.E.; HOWELL, C.R.; VITERBO, A.; CHET, I.; LORITO, M. Trichoderma species - opportunistic, avirulent plant symbionts. Nature Reviews Microbiology, v.2, p.43-56, 2004.

INTERNATIONAL Subcommission on Trichoderma and Hypocrea Taxonomy. Available at: <http://www.isth.info/>. Accessed on. 26 Dec. 2011.

IRVING, H.R.; KUĆ, J. Local and systemic induction of peroxidase, chitinase and resistance in cucumber plants by $\mathrm{K}_{2} \mathrm{HPO}_{4}$. Physiological and Molecular Plant Pathology, v.37, p.355, 1990.

KOIKE, N.; HYAKUMACHI, M.; KAGEYAMA, K.; TSUYUMU, $\mathrm{S}$; DOKE, N. Induction of systemic resistance in cucumber against several diseases by plant growth-promoting fungus: lignification and superoxide generation. European Journal of Plant Pathology, v.107, p.523-533, 2001.

KOPCHINSKIY, A.; KOMON, M.; KUBICEK, C.P.; DRUZHININA, I.S. TrichoBLAST: a multilocus database for Trichoderma and Hypocrea identifications. Mycological Research, v.109, p.658-660, 2005.

KUĆ, J.; RICHMOND, S. Aspects of the protection of cucumber against Colletotrichum lagenarium by Colletotrichum lagenarium. Phytopathology, v.67, p.533-536, 1977.

LUSSO, M.F.G.; PASCHOLATI, S.F. Activity and isoenzymatic pattern of soluble peroxidases in maize tissues after mechanical injury or fungal inoculation. Summa Phytopathologica, v.25, p.244-249, 1999.

MURRAY,M.G.; THOMPSON, W.F. Rapid isolation of high molecular weight plant DNA. Nucleic Acids Research, v.8, p.4321-4325, 1980.

NAGY, V.; SEIDL, V.; SZAKACS, G.; KOMON-ZELAZOWSKA, M.; KUBICEK, C.P.; DRUZHININA, I.S. Application of DNA bar codes for screening of industrially important fungi: the haplotype of Trichoderma harzianum sensu stricto indicates superior chitinase formation. Applied and Environmental Microbiology, v.73, p.7048-7058, 2007.

PERAZZOLLI, M.; DAGOSTIN, S.; FERRARI, A.; ELAD, Y.; PERTOT, I. Induction of systemic resistance against Plasmopara viticola in grapevine by Trichoderma harzianum T39 and benzothiadizole. Biological Control, v.47, p.228-234, 2008.

RIOS, P.R.P.; SILVEIRA, E.B.; MARTINS, L.S.S.; SILVA NETO, E.B.; GOMES, A.M.A. Caracterização de isolados de Colletotrichum lagenarium de pepino com base em marcadores isoenzimáticos. Horticultura Brasileira, v.22, p.729-733, 2004.

SANGER, F.; NICKLEN, S.; CHASE, A.R. DNA sequencing with chain terminating inhibitors. Proceedings of the National Academy of Sciences of the United States of America, v.74, p.5463-5468, 1977.

SEGARRA, G.; VAN DER ENT, S.; TRILLAS, I.; PIETERSE, C.M.J. MYB72, a node of convergence in induced systemic resistance triggered by a fungal and a bacterial beneficial microbe. Plant Biology, v.11, p.90-96, 2009.

SHORESH, M.; YEDIDIA, I.; CHET, I. Involvement of jasmonic acid/ethylene signaling pathway in the systemic resistance induced in cucumber by Trichoderma asperellum T203. Phytopathology, v.95, p.76-84, 2005.

SILVA, F. de A.S. e.; AZEVEDO, C.A.V. de. A new version of the Assistant-Statistical Assistance Software. In: WORLD CONGRESS ON COMPUTERS IN AGRICULTURE, 4., 2006, Orlando. Proceedings. Orlando: American Society of Agricultural and Biological Engineers, 2006. p.393-396.

VINALE, F.; SIVASITHAMPARAM, K.; GHISALBERT, E.L.; MARA, R.; BARBETTI, M.J.; LI, H.; WOO, S.L.; LORITO, M. A novel role for Trichoderma secondary metabolites in the interactions with plants. Physiological and Molecular Plant Pathology, v.72, p.80-86, 2008.

VITERBO, A.; HAREL, M.; HORWITZ, B.A.; CHET, I.; MUKHERJEE, P.K. Trichoderma mitogen-activated protein kinase signaling is involved in induction of plant systemic resistance. Applied and Environmental Microbiology, v.71, p.6241-6246, 2005.

WHITE, T.J.; BRUNS, T.; LEE, S.; TAYLOR, J. Amplification and direct sequencing of fungal ribosomal RNA genes for phylogenetics. In: INNIS, M.A.; GELFAND, D.H.; SHINSKY, J.J.; WHITE, T.J. (Ed.). PCR protocols: a guide to methods and applications. San Diego: Academic, 1990. p.315-322.

YEDIDIA, I.; BENHAMOU, N.; CHET, I. Induction of defense responses in cucumber plants (Cucumis sativus L.) by the biocontrol agent Trichoderma harzianum. Applied and Environmental Microbiology, v.65, p.1061-1070, 1999.

YEDIDIA, I.; BENHAMOU, N.; KAPULNIK, Y.; CHET, I. Induction and accumulation of PR proteins activity during early stages of root colonization by the mycoparasite Trichoderma harzianum strain T-203. Plant Physiology and Biochemistry, v.38, p.863-873, 2000.

YEDIDIA, I.; SHORESH, M.; KEREM, Z.; BENHAMOU, N.; KAPULNIK, Y.; CHET, I. Concomitant induction of systemic resistance to Pseudomonas syringae pv. lachrymans in cucumber by Trichoderma asperellum (T-203) and accumulation of phytoalexins. Applied and Environmental Microbiology, v.69, p.7343-7353, 2003.

YEDIDIA, I.; SRIVASTVA, A.K.; KAPULNIK, Y.; CHET, I. Effect of Trichoderma harzianum on microelement concentrations and increased growth of cucumber plants. Plant and Soil, v.235, p.235-242, 2001.

$\overline{\text { Recebido em } 27 \text { de abril de } 2011 \text { e aprovado em } 24 \text { de novembro de } 2011}$ 